Relations industrielles

Industrial Relations

\title{
Au service de la petite industrie, publication du Bureau International du Travail, Genève, 1961, 246 pp.
}

\section{Jean-Paul Deschênes}

Volume 16, numéro 4, octobre 1961

URI : https://id.erudit.org/iderudit/1021694ar

DOI : https://doi.org/10.7202/1021694ar

Aller au sommaire du numéro

Éditeur(s)

Département des relations industrielles de l’Université Laval

ISSN

0034-379X (imprimé)

1703-8138 (numérique)

Découvrir la revue

Citer ce compte rendu

Deschênes, J.-P. (1961). Compte rendu de [Au service de la petite industrie,

publication du Bureau International du Travail, Genève, 1961, 246 pp.]

Relations industrielles / Industrial Relations, 16(4), 510-510.

https://doi.org/10.7202/1021694ar

Tous droits réservés (C Département des relations industrielles de l’Université Laval, 1961
Ce document est protégé par la loi sur le droit d'auteur. L’utilisation des services d'Érudit (y compris la reproduction) est assujettie à sa politique d'utilisation que vous pouvez consulter en ligne.

https://apropos.erudit.org/fr/usagers/politique-dutilisation/ 
sur l'état des cadres dans le secteur privé de Belgique et provoquera, sans doute, des recherches plus poussées et plus méthodiques.

La littérature française en sociologie occupationnelle est tellement rare que nous ne pouvons pas ne pas saluer avec joie cette tentative d'analyser une catégorie dont l'importance est sans cesse grandissante.

\section{Gérard Dion}

Au service de la petite industrie, publication du Bureau International du Travail, Genève, 1961, 246 pp.

Rares sont les volumes s'attaquant aux problèmes de la petite industrie, quoique celle-ci «fournit de l'emploi à une fraction considérable de la maind'oeuvre industrielle et représente une forte proportion de l'ensemble des établissements industriels ».

Comme on l'indique dans l'introduction du volume, l'ouvrage est destiné avant tout aux personnes qui, du fait des responsabilités ou des fonctions qui sont les leurs, ou pour tout autre motif, se préoccupent de dispenser des conseils, de donner un enseignement ou de fournir d'autres services aux exploitants de petites entreprises industrielles. Il est aussi destiné, il va sans dire, aux chefs de petites entreprises eux-mêmes.

Après avoir défini la petite industrie et étudié son rôle dans le développement économique, on traite ensuite des caractéristiques et des besoins de la petite industrie, comme le financement, l'approvisionnement en matières premières, l'écoulement des produits, etc...

La partie la plus importante du volume étudie les « services de promotion technique » qui ont pour but de communiquer certaines connaissances et certaines informations aux directeurs et aux travailleurs de petits établissements. Leurs activités les plus importantes sont les consultations techniques, la formation professionnelle, l'information et la recherche.

Ces derniers chapitres portent sur l'aide financière et matérielle, et sur la contribution que peut apporter la coopération à la solution des problèmes de la petite industrie.
Cet ouvrage, comme toutes les autres publications du B.I.T. d'ailleurs, est excellent, et son grand mérite est de s'attaquer à des problèmes majeurs de la petite industrie qui sont trop négligés hélas, des experts du monde de l'industrie.

Jean-Paul Deschênes

«La femme au travail». Ouvrage en collaboration. Numéro spécial de la revue Esprit, 29ème année, no 295, mai 1961.

Le travail des femmes est une donnée majeure de notre époque, un fait acquis. On peut le regretter, cela ne changera rien. Il importe de l'analyser, d'en comprendre toutes les dimensions. C'est un fait récent dans l'histoire et complexe dans ses significations. Pour certains, c'est une promotion, alors que pour d'autres, c'est une forme d'esclavage. Le travail féminin est aussi un fait humain qui métamorphose la cellule familiale, modifie la distribution traditionnelle du travail entre hommes et femmes.

Ce numéro spécial d'Esprit qui tente d'évaluer le fait du travail féminin d'une manière objective a été réalisé grâce à la collaboration d'une dizaine de spécialistes en la matière. On y envisage les dimensions du problème, ses données biologiques, les contradictions sociales qu'il comporte et l'ambiguité de l'attitude feminine à son égard.

Pareille étude est indispensable à tous ceux qui veulent voir clair dans le problème du travail féminin.

GÉrard Dion

Industrialism and Industrial Man, by Clark Kerr, John T. Dunlop, Frederick Harbison and Charles A. Myers. Cambridge: Harvard University Press, 1960. 331 pp. $\$ 6$.

Voici en quelque sorte un volumesynthèse des travaux publiés à date sous l'étiquette de l'« Inter-University Study of Labor Problems in Economic Development ». Ce groupe financé largement par la Dotation Ford, se forma en 1954 autour des quatre économistes du travail Kerr (de Californie), Dunlop (de Harvard), Harbison (de Chicago, puis Princeton) et Myers (du M.I.T.), pour lesquels l'anthropologie, la sociologie et la psychologie sont des amies. 